INTERNATIONAL JOURNAL OF MULTIDisciplinARY RESEARCH AND ANALYSis

ISSN(print): 2643-9840, ISSN(online): 2643-9875

Volume 04 Issue 07 July 2021

DOI: 10.47191/ijmra/v4-i7-18, Impact Factor: 6.072

Page No.- 1006-1012

\title{
Vulnerability of Gender Based Physical Spousal Domestic Violence in Benue State, Nigeria
}

\author{
Godwin Kwanga ${ }^{1}$, Joseph Enefu ${ }^{2}$, James Ikyernum ${ }^{3}$, Patricia, I. Ali ${ }^{4}$, Onyeche Anita Makyur ${ }^{5}$ \\ 1,2,3,4 Department of Geography, Benue State University, Makurdi, Nigeria \\ ${ }^{5}$ Department of Hospitality and Tourism Management, Federal University, Wukari-Taraba State
}

\begin{abstract}
The study accessed the vulnerability of gender based physical spousal domestic violence in Benue State, Nigeria. The study adopted the secondary data from the Nigeria Demographic and Health Survey (NDHS) (2018), conducted by National Population Commission and analysed using the Statistical Package for Social Sciences (SPSS) version 20. Information's sorted were categorized, summarized and presented in exploratory formats, frequency tables and charts. The results revealed that (77.4\%) of the respondents had experienced physical violence of different forms. The study also revealed the perceived spouse's reasons for physical violence which include suspected infidelity (18.4\%) womanizing by husband (18.4\%) disobedience (15.3\%) husband taking alcohol (9.3\%), poverty (9.1\%) and inability to give birth (suspected infertility) 23 (9.1\%). The finding further revealed that many women were ever slapped by their husbands (16.4\%) while some were threw something at (8.4\%), some were kicked and dragged by their husbands, some were beaten (16.1\%) while others (19.7\%) were pushed and shook. However, only a few (2.9\%) were threatened or attacked with a weapon. The study also found that (61.3\%) of the married women who experienced spousal physical violence in the area equally sustained different forms of injuries which include: cuts/ bruises (40.9\%), eye injuries (23.1\%), dislocations/fracture (12.4\%), deep wounds (14.5\%) and broken teeth (4.3\%). The study finally established that women who experienced spousal physical violence seek and have help from their own family (71\%), their husband's family $(21 \%)$ and religious leader (8\%). The study recommended gender based violence awareness campaigns and legal protection of women in the state to protect the right of women and reduce the vulnerability of physical violence against women in the area.
\end{abstract}

KEYWORDS: Vulnerability, Gender based, Physical spousal domestic violence, married women.

\subsection{INTRODUCTION}

Gender-based violence against women has been acknowledged worldwide as a violation of basic human rights. Increasing research has highlighted the health burdens, intergenerational effects, and demographic consequences of such violence (United Nations 2006). Gender-based violence is defined by the United Nations as any act of violence that results in physical, sexual, or psychological harm or suffering to women, girls, men, and boys, as well as threats of such acts, coercion, or the arbitrary deprivation of liberty. This chapter focuses on domestic violence, mainly intimate partner violence, a significant component of gender-based violence.

In Nigeria, domestic violence is widely acknowledged to be of great concern not just from a human rights perspective but also from an economic and health perspective. In 2015, Nigeria passed the comprehensive violence against person's prohibition act 2015, which aims to eliminate all forms of violence in both the private and public spheres and includes the right to assistance for victims of violence (Federal Ministry of Women Affairs and Social Development 2015). In addition, Nigeria is a signatory to the Convention on the Elimination of All Forms of Discrimination against Women (CEDAW). Nonetheless, despite legislation and on-going efforts to protect women and vulnerable populations against violence, much remains to be done in protecting victims and prosecuting perpetrators. Nationally representative data on the prevalence of different forms of violence can help monitor progress towards the elimination of violence against persons in Nigeria.

Accordingly, the 2018 NDHS included a module of questions designed to obtain information on the extent to which women in Nigeria experience domestic violence, including both intimate partner violence and violence by perpetrators other than husbands or other intimate partners. 


\section{Vulnerability of Gender Based Physical Spousal Domestic Violence in Benue State, Nigeria}

Globally, at least one in three women has experienced some form of gender-based violence by her partner during her life time. The most common injuries suffered by victims range from battering by intimate partners and others, sexual abuse of children, marital rape, traditional practices that are harmful to women, bruises or broken bones of the victims to depression, anxiety and social isolation.

Historically violence against women in the home has been part of human life but the degree to it's prevail differs across communities/societies. Similarly, at what point societies came to terms with the repugnancy of domestic violence against women also varies. In many societies, it has been an accepted fact of life and as such many people lived with it without feeling that it was anything wrong. For instance, wife beating was tactically accepted in many countries and the police and courts may rarely take action. Rape victims often face unsympathetic legal systems as it's often directed towards female and youths who lack the economic and social status to avoid it. Because of these reasons, women who have been subjected to domestic violence, in some instances learn to accept it giving its perpetuity. Some women victims, for the fear of repeated attacks by perpetrators, refused to even report to the police.

Physical violence as one of the domestic violence types among married women can contribute to dangerous outcomes in women's health (Heaman, 2005). A study conducted in a neighboring country, Timor-Leste found that women experiencing physical violence were more likely to report sexually transmitted infections, pregnancy terminations, low birth weight infants and higher rates of child mortality Shiyun, (2013). Therefore, examining the vulnerability to domestic physical violence among married women in Indonesia remains an important issue which can be measured by their acceptance of domestic violence justification perpetrated by the husband.

Among many existing theoretical explanations for domestic and marital violence, the most evolved, and frequently referenced include feminist theories and cultural theories. These theories give both contextual and individual-level explanations for domestic violence, thus linking violence in the family to the broader society. Feminist theories explain domestic violence in relation to gender and power relations in society, including the role of the patriarchy in enacting and perpetuating female domestic abuse. Feminist scholars insist that domestic violence is sexed (Anderson, 2013), thus a means through which sexed exploitation and inequality are staged, where society places emphasis on continual female denigration and inferiority, but male superiority (D'cruze and Rao, 2005). Society prizes normative masculinity, and normative femininity, particularly highlighting a man's ability to exhibit power: a system of male authority, male rule, male-domination and control (Kimmel, 2018). Price (2005) considers specific socio-cultural ideas about societal construction of being a proper man or woman and suggests that the difference in the ways that men and women are constructed in diverse cultures perpetuates the systemic abuse of women.

Particularly in African cultures, including the Nigerian culture, gender roles are clearly defined, and male domination and control is maintained and exercised through, for example, traditional values, beliefs, and customs (Uthman, 2009). Women's experiences within the domestic sphere are shaped by socio cultural expectations of normative femininity such as passivity and submission, whereas it is expected that men exhibit normative masculinity such as aggression and domination, and traditional norms recognize men as domestic heads and breadwinners, and women as procreators and domestic caretakers (Karim, 2011).

Given the prevalence of domestic violence among spouses in the area, exploring the perpetuation of domestic violence in the state could throw more light towards the understanding of vulnerability of gender based physical spousal domestic violence in Benue State, Nigeria.

\section{MATERIALS AND METHODS}

\subsection{Study Area}

Benue State is located along latitude $6^{\circ} 25^{\prime} \mathrm{N}-8^{\circ} 8^{\prime} \mathrm{N}$ and longitude $7^{\circ} 47^{\prime} \mathrm{E}-10^{\circ} 0^{\prime} \mathrm{E}$. The State, which is located in the North Central region of Nigeria, has a total population of 4,253,641 in 2006 with an average population density of 99 persons per $\mathrm{km}^{2}$. It is inhabited predominantly by the Tiv, Idoma, Igede and Etulo people who speak Tiv, Idoma, Igede and Etulo languages respectively. Its capital is Makurdi (NPC, 2009). It is largely rural, with scattered settlements mainly in tiny compounds or homesteads, whose population range from 630 people, most of whom are farmers. Agriculture is the mainstay of the economy, engaging over $75 \%$ of the state farming population. Benue State consists of twenty-three (23) Local Government Areas as indicated on Fig 1. 


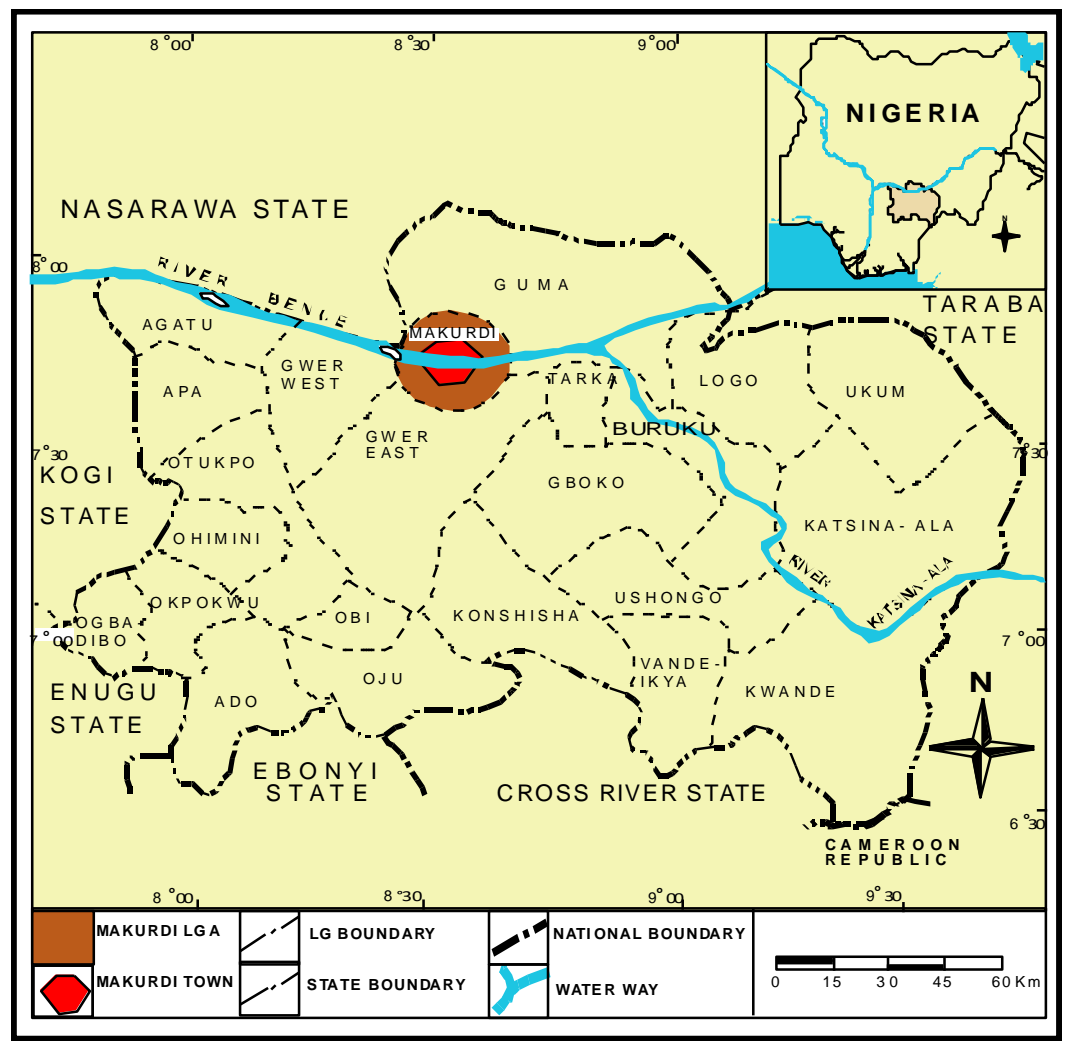

Fig 1: Benue State Showing LGAs

Source: State Ministry for Lands \& Survey, (2018)

\subsection{Methods}

This study was a quantitative study using secondary data from the Nigeria Demographic and Health Survey (NDHS) 2018, conducted by National Population Commission and ICF International. The records of individual married women of reproductive age (15-49 years old) were obtained from the 2018 NDHS. Those are current published large data sets of national representations of population-based surveys that help describe the current situation of domestic physical violence among married women in Nigeria. The sampling technique employed for the NDHS was a multi-stage random sampling, stratified by zone and state. About 354 married women were considered and selected from the area in accordance with the NDHS 2018 standard. Information was obtained from ever-married women on their experience of violence committed by anyone. All analyses were conducted using the Statistical Package for Social Sciences (SPSS) version 20. Information's sorted were categorized, summarized and presented in exploratory formats through frequency tables and charts.

\section{0}

\section{RESULTS AND DISCUSSION}

\subsection{Socio-demographic Characteristic of Respondents}

Data presented in Table I shows the socio-demographic characteristic of the respondents. The predominant age group of the respondents was $21-30$ years (52.3\%). Of all respondents, 325 (91.8\%) were Christians, and 78 (22.1\%) had no formal education. Among 276 (77.9\%) respondents who had formal education, those with secondary education predominates (52.8\%), followed by primary education (18.9\%), while those with tertiary education constitutes only $6.2 \%$. Farming (61.3\%) was the predominant occupation of the respondents. Majority of the respondents, $309(87.3 \%)$ indicated married as their marital status while $12.7 \%$ divorced. Most respondents reported that their age at first marriage was between $21-30$ years (53.4\%).

Table 1: Socio-demographic Characteristic of Respondents

\begin{tabular}{llll}
\hline Demographic characteristics & & F & \% \\
\hline Age (years) & $13-20$ & 43 & 12.1 \\
& $21-30$ & 185 & 52.3 \\
& $31-40$ & 89 & 25.1 \\
& 41 and above & 37 & 10.5
\end{tabular}


Vulnerability of Gender Based Physical Spousal Domestic Violence in Benue State, Nigeria

\begin{tabular}{llll} 
Religion & Christianity & 325 & 91.8 \\
& Islamic & 29 & 8.2 \\
& & & \\
Educational qualification & No formal & 78 & 22.1 \\
& Primary & 67 & 18.9 \\
& Secondary & 187 & 52.8 \\
& Tertiary & 22 & 6.2 \\
& & & \\
Occupation & Farming & 217 & 61.3 \\
& Civil servant & 39 & 11 \\
& Trading & 98 & 27.7 \\
Marital status & Married & 309 & 87.3 \\
& Single & - & - \\
& Divorced & 45 & 12.7 \\
Aged at first marriage & & & \\
& 11-20 & 101 & 26.5 \\
& 21-30 & 189 & 53.4 \\
Total & 31 and above & 64 & 18.1 \\
\hline
\end{tabular}

Source: NDHS, 2018

\subsection{Prevalence of physical violence among respondents}

Data on the prevalence of physical violence among the respondents presented on Table 2 show that higher percentage of respondents (77.4\%) had experienced physical violence of different forms. The data also shows that $50.3 \%$ of women who have ever been pregnant have experienced physical violence during pregnancy. This result is in congruence with the findings of Shija, (2003) who found that majority of the married women in Benue state have experienced physical violence which subsequently resulted to divorce. In similar vein, a study by Okpe, (2009) reported that majority of women are victims of spousal domestic physical violence.

Table 2: Prevalence of physical violence among respondents

\begin{tabular}{lllll}
\hline Prevalence of physical violence & Response & F & $\%$ \\
\hline $\begin{array}{l}\text { Have u ever experienced } \\
\text { violence? }\end{array}$ & & No & 80 & 274.4 \\
& & & \\
Have you ever experience & Yes & & \\
violence during pregnancy? & Yes & 178 & 50.3 \\
Total & No & 176 & 49.7 \\
\hline
\end{tabular}

Source: NDHS, 2018

Data presented on Figure 2 on the other hand indicated the perceived spouse's reasons of physical violence, there were multiple responses from the respondents. Of all the reasons cited, the most common were suspected infidelity in women cited by $65(18.4 \%)$ respondents, womanizing by husband cited by $65(18.4 \%)$ respondents and disobedience by women indicated by $54(15.3 \%)$ respondents. Other reasons advanced by respondents include husband taking alcohol $33(9.3 \%)$, poverty $23(9.1 \%)$, mental disorder of the husband $12(4.7 \%)$ and inability to give birth (suspected infertility) 23 (9.1\%). The finding is also in line with Utulu and Utulu, (2005) whose finding outlined alcohol intake, womanizing, disobedience, infidelity and infertility as the reasons behind spousal physical violence in Makurdi metropolis. 


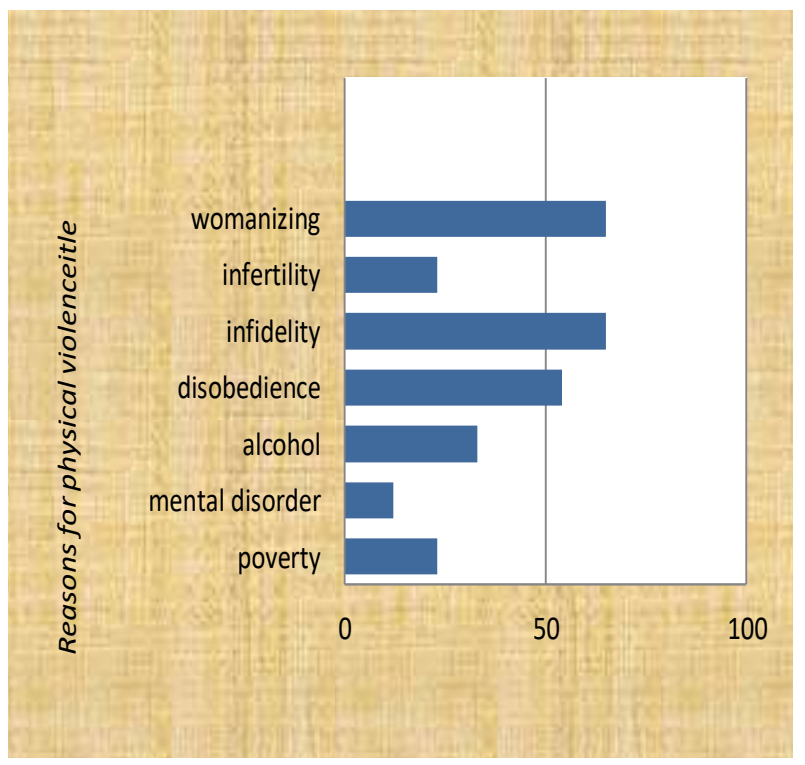

Fig 2: Perceived spouse's reasons of physical violence

Data on the forms of physical violence in the area is presented on Table 3. Women experiencing spousal physical violence most commonly reported that their husband slapped them (16.4\%). About $8.4 \%$ of women reported that their husband threw something at them while $16.1 \%$ reported that their husbands kicked, dragged them while $19.7 \%$ of the women ever experienced violence reported their husbands beat them up; $19.7 \%$ reported that their husband pushed, shook and $12.4 \%$ reported that their husband twisted their arm or pulled their hair. About $4.4 \%$ of women said that their husband tried to choke or burn them on purpose while $2.9 \%$ reported that their husband threatened or attacked them with a knife, gun, or other weapon. A study by Odey, (2005) also came out with similar findings that the forms of physical violence commonly experienced by women in Nigeria are slaps, beating, pushing. He also recorded a small percentage of women who were attacked with a weapon like knife, cutlass or a gun.

Table3: Forms of physical violence experienced by women

\begin{tabular}{lll}
\hline Form of violence & F & \% \\
\hline Pushed her, shook her, & 54 & 19.7 \\
Threw something at her & 23 & 8.4 \\
Slapped her & 45 & 16.4 \\
Twisted her arm or pulled her hair & 34 & 12.4 \\
Kicked her, dragged her & 44 & 16.1 \\
Beat her up & 54 & 19.7 \\
Tried to choke her & 12 & 4.4 \\
Threatened her with a weapon & 8 & 2.9 \\
Total & 354 & 100 \\
\hline
\end{tabular}

Source: NDHS, 2018

\subsection{Injuries to Women due to Spousal physical Violence}

Data on injuries to women due to spousal physical violence revealed that women sustained the following injuries from physical violence: cuts, bruises, or aches; eye injuries sprains, dislocations/fractures, or burns; or deep wounds, broken bones, broken teeth, or any other serious injury. Data on the form of injuries sustained by women due to physical violence presented on Table 4 indicated that among the married women who experienced spousal physical violence in the area, 186 (61.3\%) have sustained different forms injuries. Cuts and bruises are the most common type of injury (40.9\%) among women who have experienced physical violence. About $23.1 \%$ of women reported that they have sustained eye injuries, $12.4 \%$ reported to have dislocations/fracture, while $14.5 \%$ said that they have sustained deep wounds and $4.3 \%$ of them reported to have broken teeth. The findings agree with the findings of Hoque and Kader, (2009) who studied the prevalence and experience of domestic violence among rural pregnant women in Kwa Zulu-Natal, South Africa. 
Vulnerability of Gender Based Physical Spousal Domestic Violence in Benue State, Nigeria

Table 4: Injuries to women due to spousal violence

\begin{tabular}{lll}
\hline Type of injury & F & \% \\
\hline Cuts/bruises & 76 & 40.9 \\
Eye injuries & 43 & 23.1 \\
Dislocations /fracture & 32 & 12.4 \\
Deep wounds & 27 & 14.5 \\
Broken teeth & 8 & 4.3 \\
Total & 354 & 100 \\
\hline
\end{tabular}

Source: NDHS, 2018

\subsection{Sources for help against spousal physical violence}

Data on the sources of help for settlement of spousal physical violence is presented on Figure 3. Among women who have experienced physical violence and sought help, have their most common sources of help from their own family (71\%) and their husband's family (21\%) and $8 \%$ of women sought help from a religious leader. Odimegwu, (2001) in his study on couple formation and domestic violence among the Tiv people of Benue State, Nigeria came out with similar sources women seek for resolving spousal physical violence in Benue state.

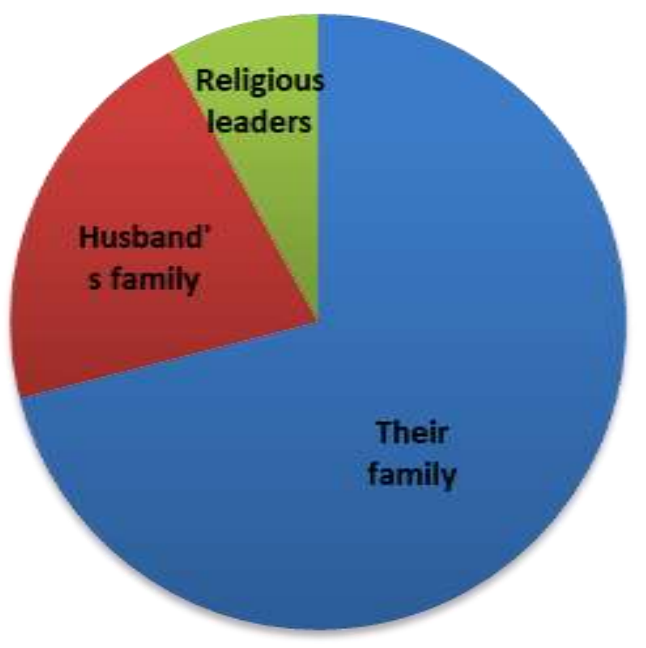

Fig 3: Sources for help against spousal physical violence

\subsection{CONCLUSION AND RECOMMENDATION}

The Vulnerability of gender based physical spousal domestic violence in Benue State, is very high with risk associated resulting to various injuries sustained by ever-married women within the ages of 15-49 years. Gender based violence awareness campaigns and legal protection of women should be encouraged in the state to protect the right of women and reduce the vulnerability of physical violence against women in the area.

\subsection{ACKNOWLEDGEMENTS}

The authors appreciate and thank the National Population Commission and ICF International for the collection of the NDHS Data Sets and making it available for use.

\section{REFERENCES}

1) Anderson, M. (2013).Understanding Domestic Violence: Definitions, scope, impact and response, The Annie E Casey Foundation.

2) Deruse, B.A and Rao M. (2005). Violence against women in Arab and Islamic countries. Women's Ment. Health 2003;6:165-71

3) Heaman, F. (2005) Effect of Early Marriage in North Western Nigeria, Mediterranean Journal of Social Sciences, 2014; Vol 5 No 14: 582-592

4) Hoque M, Hogue E. and Kader S. (2009)."Prevalence and experience of domestic violence among rural pregnant women in KwaZulu-Natal, South Africa," Southern African Journal of Epidemiology \& Infection, vol. 24, no. 4, pp. 34-37. 


\section{Vulnerability of Gender Based Physical Spousal Domestic Violence in Benue State, Nigeria}

5) Karim, A (2009). Prevalence of Domestic Violence in Nigeria: Implication for Counselling. Edo Journal of Counselling, 2(1) 1-6.

6) Kimmel, S (2018). Intimate partner violence against women in western Ethiopia: prevalence, patterns, and associated factors. BMC Public Health 2011;11:913.

7) NPC (2009). 2006 Population and Housing Tables: Benue State Priority Table Volume 2. Abuja, Nigeria. National Population Commission.

8) NPC and ICF (2019). Nigeria Demographic and Health Survey 2018. Abuja, Nigeria, and Rockville, Maryland, USA: NPC and ICF

9) Odey, M. O (2005) Violence against women in Nigeria: A casual analysis of Domestic Violence

10) Odimegwu, C.O (2001). Couple formation and domestic violence among the Tiv of Benue State, Nigeria. Paper presented at the International Colloquium Gender, Population and Development in Africa organized by UAPS, INED, ENSEA, IFORD, Abidjan.

11) Okpe, $\mathrm{O} . \mathrm{O}$ (2005). Re-conceptualizing violence against women: A critique of existing perspectives and their implications for sustainable development. In Perspectives on violence against women in Nigeria, Aboki publishers ; pg 15-36

12) Price, $T$ (2005). Society and violence against women: An Analysis of a Neglected Critical Aspect of the Women Question in Nigeria, in Review of Gender Studies in Nigeria, Maiden Issue, March; pg 20-29.

13) Shija, M. T (2003). "Domestic violence and its Impact on women Rights" paper presented at consultative forum of stakeholders to Discuss Domestic Violence in Benue State held at Gbihi Hotel 4 -5 August.

14) Shiyun, T (2013). Domestic violence among ever married women of reproductive age group in a slum area of Kolkata. Indian J Public Health 2012;56:31

15) Utulu, S.N and Utulu, R. E (2005). Pattern of Violence against Married women in tertiary institution in Makurdi. In Perspectives on violence against women in Nigeria, 1 edn Aboki publishers: pp 37-69.

16) UN (2002). "Shattering the silence of violence against women" in UN, 2002; Vol 1, no. 1.UN Chronicles Vol. 35 , issue 1.

17) Uthman O.A (2009). Are individual and community acceptance and witnessing of intimate partner violence related to its occurrence? Multilevel structural equation model. PLoS One. ; 6(12): 